\title{
Abordagem de Temas no âmbito do PIBID: Impactos do trabalho a partir de uma proposta CTS
}

\section{Themes Approach in the scope of PIBID: Impacts from a CTS proposal}

\author{
Aline dos Santos Brasil (aline1990sb@gmail.com) \\ (Universidade Federal do Pampa - Caçapava do Sul/RS) \\ Sandra Hunsche (sandrahunsche@ unipampa.edu.br) \\ (Universidade Federal do Pampa - Caçapava do Sul/RS)
}

\begin{abstract}
Resumo: Busca-se investigar qual é a influência do Programa Institucional de Bolsas de Iniciação à Docência (PIBID) na construção e aplicação de uma proposta temática CTS. Para isso, no contexto do subprojeto Física da Unipampa/Caçapava do Sul/RS, foi construída uma proposta de ensino balizada pelo enfoque Ciência Tecnologia Sociedade (CTS), sendo aplicada em uma turma de segundo ano do Ensino Médio, de uma escola da rede pública da cidade. Para a obtenção dos dados, foi conduzida uma entrevista com três pibidianos, além de um diário de bordo escrito durante a implementação. A análise dos dados foi feita por meio da Análise Textual Discursiva. Os resultados foram organizados por meio de três categorias: i) Interdisciplinaridade da proposta e a formação inicial; ii) Desafios na escolha do tema; iii) Proposta CTS versus envolvimento dos alunos. Desta forma, apontam-se dificuldades de realização do trabalho interdisciplinar, as quais foram amenizadas devido às intervenções realizadas no contexto do PIBID e pelo referencial teórico adotado. Também é possível destacar que o tema escolhido impactou na participação dos alunos em sala de aula, assim como contribuiu para as discussões referentes aos aspectos sociais.
\end{abstract}

Palavras-chave: CTS; Formação Inicial de Professores; Física.

Abstract: The work seeks to investigate the influences of the Institutional Program for Teaching Initiation Scholarships (PIBID) in the construction and application of a CTS thematic proposal. Therefore, in the context of the subproject Physics of Unipampa/Caçapava do Sul/RS, a teaching proposal was built based on the Science Technology Society (STS) approach, being applied in a second year class of High School, in the city. To obtain the data, an interview was conduct with three pibidians, in addition to a logbook written during implementation. To analyze the data, we used Textual Discursive Analysis. Three categories organize the results: i) Interdisciplinary of the proposal and initial training; ii) Challenges in choosing the theme; iii) STS proposal versus student involvement. Thus, we pointed difficulties in carrying out interdisciplinary work, difficulties alleviated due to the interventions carried out in the context of PIBID and due to the theoretical framework adopted. It is also possible to highlight that the chosen 
theme affect the participation of students in the classroom, as well as contributed to the discussions regarding social aspects.

Key words: STS; Initial Teacher Training; Physics.

\section{INTRODUÇÃO}

A fim de superar o ensino disciplinar e descontextualizado, Lopes (2002) sinaliza a importância da contextualização em sala de aula para o processo de construção do conhecimento, visto que tal perspectiva busca fazer relações com o cotidiano dos alunos. O autor ainda ressalta que o ensino contextualizado contribui para que o educando supere a condição de simples expectador, permitindo que se constitua como sujeito principal no seu processo de aprendizagem.

Os Parâmetros Curriculares Nacionais para o Ensino Médio (PCNEM) (BRASIL, 2000) destacam a importância de o indivíduo ser preparado para elaborar pensamentos autônomos e críticos, e para formular os seus próprios juízos de valor, de modo a poder decidir por si mesmo, frente as diferentes circunstâncias da vida. As Orientações Curriculares Nacionais para o Ensino Médio (OCNEM) (BRASIL, 2006) revelam que preparar o jovem para participar de uma sociedade complexa como a atual é um grande desafio. Para tal, estes documentos sugerem a organização dos conceitos científicos por meio de temas estruturadores e eixos temáticos. De forma similar, outros referenciais teóricos têm sinalizado para uma abordagem conceitual a partir de temas, a exemplo dos Temas Geradores Freireanos (DELIZOICOV; ANGOTTI; PERNAMBUCO, 2002), e os temas fundamentados no enfoque Ciência-Tecnologia-Sociedade (CTS) (SANTOS; MORTIMER, 2000; AULER, 2002).

Contudo, segundo Marques (2015), as efetivas mudanças educacionais acontecem a partir das práticas de sala de aula, o que implica na correspondente formação de professores. Ou seja, é necessário que a abordagem de temas seja trabalhada com os professores em formação, pois, é dessa maneira que os futuros professores se sentirão seguros em suas práticas educativas por meio de temas (HUNSCHE, 2015).

Ainda, de acordo com Hunsche (2015), além da importância de a perspectiva temática ser tratada em componentes curriculares, o Programa Institucional de Bolsas de 
Iniciação à Docência (PIBID) se constitui como um importante espaço para o desenvolvimento e aprimoramento de práticas pedagógicas fundamentadas na abordagem de temas. Assim, o problema de pesquisa que orientou este trabalho, realizado para obtenção de grau de curso de Licenciatura, consiste em: qual é a influência do PIBID na construção e aplicação de uma proposta temática CTS?

Nesta perspectiva, neste trabalho busca-se avaliar de que forma o PIBID influencia na construção e aplicação de abordagem de temas CTS por licenciandos. Assim, visa-se: i) identificar de que forma o PIBID pode se constituir em espaço de aprimoramento de discussão e elaboração de propostas temáticas; ii) caracterizar as possibilidades e dificuldades da elaboração, e implantação de uma proposta de ensino balizada pela abordagem de temas.

\section{ABORDAGEM DE TEMAS CIÊNCIA TECNOLOGIA SOCIEDADE}

Na literatura são encontradas diversas formas de abordagem de temas em sala de aula, além dos temas estruturadores e eixos temáticos (BRASIL, 2000; 2006), a exemplo da Abordagem Temática Freireana, da Situação de Estudo e da abordagem de temas balizada pelo enfoque CTS (HUNSCHE, 2015). Neste trabalho estaremos enfocando a perspectiva CTS.

É importante destacar que não há uma compreensão e um discurso consensual quanto aos objetivos, conteúdos, abrangência e modalidades de implementação do enfoque CTS no contexto educacional brasileiro, acarretando em diversas tendências e modalidades curriculares (AULER, 2002; SANTOS; MORTIMER, 2000). No entanto, de acordo com Auler (2008), existe certa unanimidade quanto à defesa de configurações curriculares pautadas pela abordagem de problemas de relevância social, visando outrossim a superação da excessiva fragmentação curricular, com o desenvolvimento de ações interdisciplinares.

Halmenschlager (2011), ao analisar artigos que abordam currículos envolvendo CTS, afirma que estes buscam discutir as influências do desenvolvimento da Ciência no cotidiano com o objetivo de formar cidadãos capazes de ler, interpretar e pensar sobre o mundo. De forma similar, Strieder (2012) afirma que a aplicação do CTS se efetiva no 
preparo dos estudantes para o seu papel em uma sociedade democrática no sentido de buscar alternativas para aplicações da ciência e da tecnologia, para o favorecimento da sociedade em geral. Em virtude disso, reconhece-se que o enfoque CTS é capaz de proporcionar um olhar integralizando a ciência, a tecnologia e a sociedade.

No enfoque CTS, segundo Strieder (2012), a ciência vai muito além de conceitos cognitivos, mas articulada relacionando valores cognitivos e sociais. A autora também destaca que a tecnologia está diretamente relacionada ao desenvolvimento social e que a ciência e a tecnologia podem interferir no desenvolvimento e no bem-estar da sociedade. Desta forma, entende-se que as relações entre a ciência, a tecnologia, e a sociedade podem vir a contribuir para o desenvolvimento educacional como um todo.

Levando em consideração a promoção da cidadania, acredita-se que a preocupação com o aspecto relacionado à formação social dos alunos, deve estar presente na escolha do tema que será abordado em sala de aula. Conforme Halmenschlager (2011), os temas articulados em CTS devem, de alguma forma, possibilitar discussões relacionadas à tecnologia, à sociedade e à conscientização sobre implicações sociais, ambientais e culturais, os temas podem ser tanto relacionados à realidade local do aluno, quanto a assuntos mais amplos.

Por outro lado, surge a preocupação de como será a escolha do tema, visto que, de acordo com Auler, Dalmolin e Fenalti (2009), com base em revisão bibliográfica, a escolha do tema na maioria das vezes é feita pelo professor, sem a participação dos alunos. Desta forma, é importante destacar a importância de selecionar temas educacionalmente relevantes, de maneira a permitir que os alunos possam construir conhecimentos importantes para sua formação.

Assim, entende-se que se o tema escolhido for de importância para a comunidade escolar, este pode contribuir no andamento das aulas. Conforme Marcondes et al. (2009) a abordagem CTS pode promover o interesse pela ciência, e aprimorar a participação e criticidade dos alunos, permitindo o desenvolvimento de associações entre a ciência, a tecnologia, e as questões sociais presentes na atualidade.

Marcondes et al. (2009) também ressaltam que o trabalho em sala de aula a partir de temas com enfoque CTS concede ao aluno o desenvolvimento da autonomia e da 
atuação da comunidade onde vivem, por meio de ações políticas, econômicas e ambientais.

Ainda sobre o enfoque CTS, é relevante ressaltar que tal perspectiva possibilita a realização de um trabalho interdisciplinar na escola. Nascimento e von Linsingen (2006) afirmam que o enfoque CTS, caracteriza-se como uma das formas de romper com o tradicionalismo curricular, valorizando a interdisciplinaridade.

Além disso, Pátaro e Bovo (2012), discutem que a fragmentação das disciplinas curriculares contribui para a desvinculação entre o conhecimento construído pelo aluno e a realidade dos problemas vivenciados na sociedade. Ainda neste contexto, Fazenda (2002) enfatiza que a interdisciplinaridade na escola deve ser baseada no diálogo e no trabalho coletivo, e que essa coletividade não deve ser somente entre disciplinas, mas também entre os professores.

\section{PIBID COMO ESPAÇO DE ELABORAÇÃO E PRÁtICA DE DIFERENTES PERSPECTIVAS EDUCACIONAIS}

O Programa Institucional de Bolsas de Iniciação à Docência (PIBID) é uma proposição da Coordenação de Aperfeiçoamento de Pessoal de Nível Superior (CAPES) que oferece bolsas a licenciandos, permitindo aos acadêmicos de cursos de licenciatura a vivência de novas experiências ao longo de sua graduação (OLIVEIRA, 2014). O conhecimento construído pelos acadêmicos, através destas experiências no âmbito do PIBID, proporciona o amadurecimento em relação ao futuro profissional docente, desenvolvendo o espírito de coletividade e uma visão crítica (BRAIBANTE; WOLLMAN, 2012).

O programa busca a valorização docente na formação inicial de professores, bem como a formação continuada de docentes atuantes na Rede Básica de Ensino, por meio dos professores supervisores, além de permitir aos acadêmicos dos diferentes cursos de licenciatura a vivência de experiências que contribuam para a formação dos mesmos. É evidenciado que o PIBID busca a realização de atividades diferenciadas nas escolas, com o envolvimento dos professores de Educação Básica: 
[...] O Pibidiano espera que os professores consigam modificar o estilo das suas aulas, trabalhando diferentes atividades, envolvendo a turma e saindo do método tradicional, em que os alunos têm a função de memorizar e reproduzir, facilitando a introdução do ensino diferenciado por parte dos Pibidianos. (OLIVEIRA, 2014, p. 10).

O PIBID está presente nos Cursos de Licenciatura da Universidade Federal do Pampa (UNIPAMPA). No campus Caçapava do Sul/RS, o Curso de Ciências Exatas e da Terra Licenciatura oferece entrada única, podendo os alunos optarem por uma das quatro áreas de formação no decorrer do curso: Ciências Naturais, Física, Matemática ou Química. De acordo com o projeto de curso (PPC):

O curso oferecerá entrada única anual, com 100 vagas a partir do ingresso em 2014, em tempo integral nos turnos noturno e vespertino incluindo os sábados. O ingresso do acadêmico será no Curso de Ciências Exatas e da Terra - Licenciatura e, dependo do percurso escolhido, obterá uma das seguintes titulações: 1. Ciências Naturais - Licenciatura; 2. Física Licenciatura; 3. Matemática - Licenciatura; 4. Química - Licenciatura. (UNIPAMPA, 2013, p. 40).

Assim, o campus Caçapava do Sul contava, até a realização desta investigação, com três ${ }^{1}$ subprojetos do PIBID, nas áreas da Física, Matemática e Química. Ressalta-se que os bolsistas não eram escolhidos de acordo com a área de formação pretendida, havendo a possibilidade dos licenciandos atuarem em qualquer um dos três subprojetos. Desta forma, o subprojeto da área da Física possui, em seu grupo de bolsistas, não somente licenciandos da área da Física, mas também das áreas da Química, Matemática e Ciências Naturais. Tal condição pode estar sendo favorecida pela forma como o curso é estruturado e pelos docentes atuantes no processo de formação dos graduandos, como pode ser visto no PPC do curso:

[...] Para cumprir com este propósito, o quadro docente atual abriga professores com formação em áreas da educação, do ensino de ciências e das áreas específicas (Física, Matemática e Química) com conhecimento e experiências para oferecer uma formação dos acadêmicos numa perspectiva interdisciplinar e integradora das Ciências Exatas e da Terra. (UNIPAMPA, 2013, p. 33).

Deste modo, pensando na promoção das condições que valorizem a interdisciplinaridade, através do incentivo promovido pelo curso, o subprojeto Física buscou trabalhar com o estudo de referenciais que enfatizam o ensino por meio de

${ }^{1}$ A conclusão em Ciências Naturais ainda não estava em funcionamento quando da submissão do projeto PIBID à Capes, o que justifica a existência de três subprojetos e não quatro. 
temas, e com a construção de propostas temáticas. Isso vai ao encontro dos resultados de pesquisa realizada por Leal (2017), em que ressalta que os integrantes do PIBID deste subprojeto possuem maior conhecimento sobre a elaboração de propostas temáticas, e que além disso possuem a oportunidade de construírem um domínio sobre os referenciais teóricos que tratam da importância do ensino a partir de temas.

Assim, com o objetivo de proporcionar aos licenciandos atividades que possam contribuir para sua formação crítica e social, o subprojeto Física propõe a estruturação das aulas com base na abordagem de temas. Isto, por acreditar que o PIBID se caracteriza como um espaço com forte potencial para que os estudantes dos Cursos de Licenciatura possam vivenciar tais perspectivas, tanto na sua elaboração, exigindo dos bolsistas o estudo da conceituação científica, quanto no desenvolvimento destas propostas em sala de aula em escolas de Educação Básica.

Assim, é no contexto do PIBID que este trabalho foi desenvolvido, conforme detalhamento no percurso metodológico descrito a seguir.

\section{PERCURSO METODOLÓGICO}

Sob o contexto de se posicionar como sujeito e objeto de pesquisa, foi elaborada e aplicada uma proposta de ensino com viés interdisciplinar, tendo como tema "Votorantim em Caçapava do Sul: Vantagens e Desvantagens", durante as ações do PIBID - subprojeto Física, do campus de Caçapava do Sul/RS.

O tema foi escolhido tendo como premissas: i) os documentos oficiais (BRASIL, 2000; 2002), os quais sugerem que sejam abordados, em sala de aula, temas relacionados ao cotidiano do aluno; e ii) a relevância do tema para a comunidade de Caçapava do Sul, visto que há discussões sobre a retomada da exploração de metais na localidade de Minas do Camaquã situada no município acima citado, discussões que remetem a diferentes opiniões sobre o assunto. Assim, considerou-se importante discutir esse tema também em sala de aula.

A proposta seguiu o desenvolvimento tendo como suporte aproximações com o enfoque CTS, a fim de envolver o aluno da escola através de um tema atual e de importância para a comunidade. Sua organização segue a dinâmica dos Três Momentos 
Pedagógicos, os quais consistem em: Problematização Inicial: apresentam-se questões ou situações reais que os alunos conhecem e presenciam e que estão envolvidas nos temas. Nesse momento pedagógico, os alunos são desafiados a expor o que pensam sobre as situações, a fim de que o professor possa ir conhecendo o que eles pensam. Para os autores, a finalidade desse momento é propiciar um distanciamento crítico do aluno ao se defrontar com as interpretações das situações propostas para discussão e fazer com que ele sinta a necessidade da aquisição de outros conhecimentos que ainda não detém. Organização do Conhecimento: momento em que, sob a orientação do professor, os conhecimentos necessários para a compreensão dos temas e da problematização inicial são estudados; Aplicação do Conhecimento: momento que se destina a abordar sistematicamente o conhecimento incorporado pelo aluno, para analisar e interpretar tanto as situações iniciais que determinaram seu estudo quanto outras que, embora não estejam diretamente ligadas ao momento inicial, possam ser compreendidas pelo mesmo conhecimento (DELIZOICOV; ANGOTTI, 1992).

A proposta foi aplicada em uma turma ${ }^{2}$ composta por treze alunos do segundo ano do Ensino Médio de uma escola da rede pública da cidade de Caçapava do Sul, totalizando dez horas-aula de intervenção.

Buscou-se com a aplicação da proposta compreender o tema debatido, através do estudo de conceitos de Biologia, Matemática e Química, reconhecendo desta forma a interdisciplinaridade do tema. Os conceitos estudados serviram para entender quais os efeitos dos metais explorados no organismo humano, quais possíveis impactos ambientais, como estes metais comportam-se quimicamente e qual a importância destes no cotidiano da sociedade, bem como, as questões econômicas envolvidas na exploração.

A proposta teve como objetivo geral discutir e compreender o que a instalação da Empresa Votorantim pode proporcionar à cidade de Caçapava do Sul, com a sua atuação e exploração nas Minas do Camaquã. Para isto, foram realizadas discussões e pesquisas orientadas sobre o tema, e ainda leituras de reportagens, entrevistas com a

\footnotetext{
${ }^{2}$ A implementação da proposta foi feita em uma das turmas em que as atividades do PIBID - Subprojeto Física eram desenvolvidas.
} 
comunidade e debates entre os alunos sobre o posicionamento de cada um frente à instalação da empresa na cidade.

Para a obtenção de informações que respondessem aos objetivos deste trabalho, foi realizada entrevista com três integrantes do PIBID, subprojeto da área da Física, escolhidas tendo como critério o fato de integrarem o grupo de trabalho juntamente com a autora da pesquisa. Para manter o anonimato, as bolsistas entrevistadas são denominadas como Bolsistas A, B e C.

As questões que orientaram a entrevista consistiam em: 1. Como você se sentiu frente a elaboração da proposta?; 2 . O que foi necessário para a elaboração da proposta? Houve contribuição do curso para a elaboração da proposta?; 3. Qual é o papel dos colegas no processo de elaboração? Comente; 4. Qual a influência da elaboração e implementação de temáticas na formação de professores? E no processo de ensinoaprendizagem nas escolas?

Além disso, foi elaborado um diário de bordo ou diário de aula (ZABALZA, 2004) por uma das autoras deste trabalho durante a elaboração da proposta e sua posterior aplicação na escola, o qual descreveu situações vivenciadas em sala de aula, e também aspectos emocionais como dúvidas, anseios, frustrações e contentamentos. Zabalza (2004) denomina como Diários de Aula a ferramenta que pode ser utilizada tanto com a finalidade investigadora, quanto com a orientadora para o desenvolvimento pessoal e profissional de quem o escreve. Os trechos do diário são identificados como $\mathrm{DB}$, juntamente com a data em que cada uma das reflexões foi escrita.

A análise das informações oriundas destes instrumentos ocorreu por meio da Análise Textual Discursiva (ATD) (MORAES; GALIAZZI, 2011). A ATD constitui-se de um ciclo de análise dividido em três momentos, quais sejam: (i) unitarização; (ii) categorização; (iii) comunicação. No momento da (i) unitarização, o pesquisador, faz a leitura dos textos ou falas que constituem seu material de análise, e deles retira trechos que expressem significados e representem o fenômeno estudado. Em seguida, agrupa os trechos em (ii) categorias, que surgem à medida que, dos textos desconstruídos, o pesquisador começa a estabelecer relações, ou podem ser estabelecidas a partir da teoria que subsidiará a análise. Encerrando o ciclo está o processo de (iii) comunicação dos 
resultados que se dá a partir da construção de textos que expressem o conjunto de significados construídos durante a análise. Este último momento pode recomeçar o ciclo já que a partir de novas leituras podem-se atingir níveis mais profundos de compreensão, surgindo novos significados.

\section{RESULTADOS}

A partir da análise do diário de bordo e da transcrição das entrevistas, emergiram três categorias, quais sejam: i) Interdisciplinaridade da proposta e a formação inicial; ii) Desafios na escolha do tema; iii) Proposta CTS versus envolvimento dos alunos.

\section{i) Interdisciplinaridade da proposta e a formação inicial}

A interdisciplinaridade é uma questão discutida quando se trata do trabalho a partir de temas, e não só neste contexto, mas em todo cenário educacional, pois entendemos que a interdisciplinaridade busca a integração das diversas áreas de conhecimento e dessa forma contribuir para a desfragmentação do ensino.

Contudo, ainda existe uma compreensão deturpada quando o assunto é a interdisciplinaridade na sala de aula. Tanto nas entrevistas quanto no diário de bordo, nota-se uma compreensão de que a interdisciplinaridade está em um único docente, conforme pode ser observado nas falas que seguem:

[...] Tive um pouco de dificuldade em fazer a articulação dos conteúdos, porque as vezes a gente tem um maior domínio em uma determinada área, e trabalhando com temas a gente vai ver que é preciso explorar várias áreas. (Bolsista B).

[...] Tenho também uma dificuldade em deixar a proposta interdisciplinar, pois como apresento maior afinidade pela área da química, consigo ter mais facilidade com os conceitos químicos necessários para compreensão do tema. (DB 02/11/2016).

Os trechos demonstram preocupação em tentar realizar um trabalho interdisciplinar, principalmente em dominar outras áreas. Embora a compreensão, pelos alunos, de temas tais como o desenvolvido neste trabalho exija conhecimentos de várias áreas, é preciso atentar para o fato de que não é um professor que deve dominar todas as áreas. Outrossim, a interdisciplinaridade requer o trabalho coletivo, de planejamento e 
execução, de toda equipe de professores de uma escola, como já citado em Fazenda (2002).

$\mathrm{O}$ aspecto aqui destacado mostra a falta de clareza dos licenciandos quanto ao aspecto interdisciplinar. É possível que isso seja decorrente da característica interdisciplinar da licenciatura que estes cursam. Isto pode estar fazendo com que os licenciandos criem uma imagem de que precisam estar aptos a lecionar todas as áreas formativas propostas pelo Curso de Ciências Exatas Licenciatura.

Porém, no decorrer da aplicação da proposta, o diário de bordo sinaliza a superação deste olhar, quando há o registro de que esse trabalho interdisciplinar não deve ser realizado por uma só pessoa, e sim por várias.

[...] Sinto que seria mais rica a aula se a proposta fosse desenvolvida em conjunto com professores de outras áreas, como, a Matemática, e a Biologia, pois apesar do curso proporcionar uma visão interdisciplinar, não há como dominar todas as áreas. (DB 28/09/2017).

É importante enfatizar que, no contexto escolar, a interdisciplinaridade refere-se ao trabalho coletivo dos professores, às discussões coletivas frente a diversos assuntos, e dessa forma a interligação entre as áreas do conhecimento e os conceitos envolvidos.

É evidente que, inicialmente, não havia clareza de como deveria ocorrer a interdisciplinaridade nas aulas. Porém, a proximidade com o enfoque CTS da proposta em questão, e reconhecendo-se que tal perspectiva valoriza a interdisciplinaridade, como observado no referencial teórico em Nascimento e von Linsingen (2006), é possível afirmar que ao decorrer das aulas construiu-se uma concepção mais clara sobre a interdisciplinaridade.

Outro ponto positivo, que atualmente colabora para o desenvolvimento de propostas baseadas em temas e auxilia na contemplação da interdisciplinaridade, é o PIBID, pois, como já destacado anteriormente, os subprojetos do campus Caçapava do Sul, não selecionavam os bolsistas por área de formação oferecida pelo curso. Essa estrutura parece estar favorecendo a formação dos licenciandos, como destacado na fala de uma das entrevistadas:

[...] Eu acho que o papel dos colegas é essencial, digamos, porque quando a gente for trabalhar na escola, se for segundo os referenciais todos eles trazem 
a interdisciplinaridade, que precisamos trabalhar em grupo com os outros professores, e quando a gente está elaborando aqui na faculdade, e no PIBID, uma proposta, muitas vezes a gente trabalha com colegas de áreas diferentes, isso já vai nos preparando digamos para o futuro. (Bolsista $\mathrm{A}$ ).

Conforme a análise da fala, percebe-se que o PIBID possibilita a integração das áreas do conhecimento, o que pode contribuir para desfragmentação do ensino e a valorização da interdisciplinaridade, pontos estes que promovem a melhoria de questões relacionadas ao ensino e aprendizagem nas escolas. Tal afirmação é evidenciada por Bonatto et al. (2012), quando afirmam que "A interdisciplinaridade é um elo entre o entendimento das disciplinas nas suas mais variadas áreas. Sendo importante, pois, abrangem temáticas e conteúdos permitindo dessa forma recursos inovadores e dinâmicos, onde as aprendizagens são ampliadas". É preciso destacar que, assim como afirmam os autores, a interdisciplinaridade não requer eliminar as disciplinas, trata-se de torná-las comunicativas entre si.

Deste modo, entende-se que tanto o curso quanto o PIBID contribuem para a construção da identidade profissional, auxiliando na constituição de um docente, preparado para o trabalho coletivo. Apesar de apresentar dificuldades frente a questões interdisciplinares, o licenciando busca vencer tais barreiras, o que pode vir a contribuir para o processo de ensino e aprendizagem em sala de aula.

\section{ii) Desafios na escolha do tema}

A escolha do tema é importante na elaboração e aplicação de uma proposta temática, pois é através do tema que serão organizados os conceitos envolvidos, e isso pode interferir diretamente na forma como serão conduzidas as aulas, no aprendizado dos alunos e no desempenho do papel do professor.

Através da elaboração e aplicação da proposta temática, algumas constatações foram possíveis. Com base no diário de bordo, é válido afirmar que uma das dificuldades relacionadas à elaboração da proposta é em relação à escolha do tema:

\footnotetext{
Apesar do tema escolhido ser atual tenho receio que a comunidade escolar onde eu for aplicar a proposta, não esteja interessada neste assunto, e que eu não consiga chamar a atenção para tudo que está envolvido no contexto desta proposta. (DB 02/11/2016).
} 
O trecho do diário demonstra a insegurança da licencianda em relação à escolha do tema a ser trabalhado, e se o tema será relevante para os alunos.

Porém o trabalho com propostas balizadas em temas possibilita contribuir na formação da cidadania dos alunos, pois oferece condições para que estes se tornem sujeitos reflexivos e capazes de opinar. Reconhecendo, a partir daí a responsabilidade da escolha do tema, umas das bolsistas entrevistadas evidencia em sua fala que:

[...] Uma proposta temática vai possibilitar ao aluno, um momento de discussões em sala de aula. Partindo de um tema da realidade local dos alunos é muito importante porque vai motivar a participação dos mesmos em sala de aula. Eu acho que com a proposta eu posso pensar o que eu quero que meu aluno aprenda. Quais as habilidades esse aluno tem que desenvolver, acho que assim podemos alcançar a formação social do aluno. (Bolsista B).

A escolha da temática a ser trabalhada, de certa forma, determina também qual será a maneira de participação dos alunos. No contexto dessa pesquisa, revela-se que o tema trabalhado já era de conhecimento dos alunos, pelo fato de já terem discutido o assunto em outra disciplina, o que em alguns casos pode ter contribuído para a participação nas aulas, e em outros casos, ao contrário, pode ter ocorrido o desinteresse, por não se tratar de um assunto novo.

Essa falta de participação dos alunos, contribui em certas ocasiões para a desmotivação da autora, como é possível perceber em uma de suas reflexões: "nem todos participaram, isso que me deixou um pouco triste e desmotivada" (DB 24/08/2017).

Por outro lado, em vários momentos, o tema escolhido possibilitou a discussão entre os alunos, mobilizando conhecimento científico e construindo conhecimento escolar. Assim, mesmo havendo o enfrentamento de algumas dificuldades durante a aplicação da proposta, é importante relatar que a autora reconhece o trabalho com temas como um meio de trabalhar a formação social dos alunos, como é visto no diário de bordo:

"Fico contente quando os alunos contribuem e dão exemplos sobre o que é discutido em sala de aula, a aplicação da proposta permite que eu discuta com eles questões sociais e do dia a dia deles". (DB 28/09/2017). 
A seleção do tema também implica na organização e na seleção dos conceitos envolvidos na proposta. A respeito disso, ressalta-se a dificuldade em selecionar os conceitos necessários para compreensão do tema, de uma forma que os mesmos não sejam abordados de uma maneira muito superficial, e nem aprofundada que fujam do foco da proposta temática. Esta afirmação pode ser identificada no trecho do diário da autora:

[...] Não sei como encaixar os conteúdos que são relevantes para a compreensão do assunto, sem ao mesmo tempo entrar mais a fundo nesses conceitos. Eu fico pensando que tal conceito é importante para compreender o tema, como por exemplo, elementos químicos, mas como trabalhar elementos químicos, sem trabalhar com tabela periódica? Uma coisa puxa a outra, é muito complicado, não sei como fazer, acho que o que está me faltando principalmente, é isto, saber organizar os conceitos, para colocar na proposta, saber dosar esses conceitos, para que sejam suficientes para que os alunos consigam compreender o tema." (DB 14/03/2017).

Levando em consideração as informações analisadas, torna-se pertinente afirmar que, apesar de algumas dificuldades serem vivenciadas no contexto da elaboração e aplicação de propostas temáticas, tal perspectiva é relevante tanto para o crescimento do aluno enquanto sujeito na sociedade, quanto para o professor na formação inicial, visto que este adquire a capacidade de desenvolver a aprimorar a autonomia em sala de aula.

Além disso, é importante ressaltar que, apesar de uma parcela mínima dos alunos não apresentarem uma participação desejada, o tema escolhido contribuiu para vários momentos de discussões. Afirma-se ainda que a insegurança na escolha do tema, bem como em relação à postura dos alunos frente ao tema escolhido, pode ser atribuída ao viés CTS, em que o professor, em geral, escolhe o tema, acarretando no desinteresse dos alunos (AULER, DALMOLIN e FENALTI, 2009).

Também é válido relatar que pelo fato da licencianda que implementou a proposta já ter contato com os referenciais que abordam o trabalho a partir de temáticas, e que por este fato ser aprimorado no contexto do PIBID, de uma certa forma, mesmo havendo insegurança em alguns momentos, a escolha do tema foi feita com a intenção de contribuir para a comunidade escolar. Assim confirmando o que é ressaltado por Martins e Veiga (1999), que reconhecem a importância da formação do aluno, e do professor como mediador deste processo. 


\section{iii) Proposta CTS versus envolvimento dos alunos}

O trabalho envolvendo temas permite contribuir para a construção do conhecimento dos alunos, tanto na parte científica, quanto na parte social. Os temas com aproximação CTS, em geral, possibilitam as discussões em torno de questões sociais, de modo que professor e aluno podem se posicionar frente a assuntos do cotidiano, refletirem sobre estes assuntos, e possivelmente serem capazes, de através do conhecimento, ter condições de intervir na sociedade onde vivem.

A aplicação da proposta intitulada: Votorantim em Caçapava do Sul: Vantagens e Desvantagens, que tratou da instalação da empresa Votorantim em Caçapava do Sul e da retomada da exploração dos minérios na localidade das Minas do Camaquã, possibilitou a discussão sobre assuntos sociais, relacionados a questões importantes que envolvem a cidade. Tal afirmação pode ser observada em algumas reflexões do diário de bordo da autora:

[..] Questionei eles: "Mas e pra cidade vocês acham que é bom essa retomada na exploração?". Alguns alunos responderam que não. Disseram o seguinte: “Não, o lucro pra cidade será muito pouco". (DB 24/08/2017).

[...] Percebi que a maioria dos alunos são contra a exploração pela Votorantim. Uma aluna apontou nas respostas que é contra ao projeto, devido aos malefícios que irá trazer, questionei: "Malefícios? Quais?". Ela me respondeu: "Ao meio ambiente, ao rio, problemas respiratórios". (DB 24/08/2017).

[...] Neste dia trabalhei com os alunos as questões ambientais e as questões econômicas da exploração dos metais, expliquei o que são metais pesados, questionei o que eles sabiam sobre o investimento e a porcentagem que será repassada pela empresa, e depois disponibilizei a reportagem que tratava das questões econômicas. (DB 28/09/2017).

As reflexões retratam o trabalho realizado na aplicação da proposta e alguns dos assuntos discutidos. A partir dos trechos é possível ressaltar que houve participação dos alunos, quando as discussões são referentes às questões sociais e ambientais que os afetam diretamente, o que permite reconhecer a importância do trabalho com propostas temáticas, particularmente, aquelas balizadas por temas que tenham relevância direta à vivência do educando. Isto reforça as discussões tecidas na categoria anterior, quanto à relevância do tema escolhido. 
Durante a aplicação da proposta na escola, foi sugerido que os alunos realizassem uma entrevista com algumas pessoas da comunidade onde vivem, isso possibilitou ainda mais a discussão em torno de questões sociais. Uma das perguntas da entrevista foi a seguinte: "O que você pensa a respeito da retomada da exploração nas Minas do Camaquã?". É possível sinalizar que a comunidade entrevistada conhece o assunto de uma forma bastante superficial, como pode-se observar nas falas de alguns alunos, e da autora, contidos no diário de bordo:

[...] Uma aluna falou que as pessoas que ela entrevistou não sabiam nada sobre a retomada da exploração pela Votorantim, que mesmo sendo um assunto atual e que de uma forma afeta a cidade, a população em geral não fica sabendo do que acontece. (DB 19/10/2017).

[...] Falei com eles que muitas coisas acontecem dessa forma, a população é carente de informação, e por isso muitas vezes não sabem opinar sobre alguns assuntos, comentei com os alunos neste momento a importância do conhecimento, de sabermos nos posicionar em todos os assuntos. (DB 19/10/2017).

[...] Os alunos também relataram que as pessoas que dizem ser a favor da retomada da exploração nas Minas do Camaquã pensam que a cidade e a localidade das minas irão crescer muito, mas desconhecem a porcentagem do lucro que será destinada à cidade. (DB 19/10/2017).

A partir dos trechos expostos, observa-se a importância de trabalhar a educação social em sala de aula, para que os alunos saibam se posicionar e intervir em questões do dia a dia. Desse modo, reconhece-se que a abordagem de temas na escola permite que tal visão social seja aprimorada.

Além disso, Marcondes et al. (2009) destacam que a introdução da abordagem CTS nas aulas de ciências possibilitaria romper com a imagem neutra da ciência, despertando maior interesse por parte do aluno pela Ciência, ajudando na resolução de problemas de ordem pessoal e social, de forma que o aluno tenha um envolvimento mais atuante nas questões sociais, políticas, econômicas e ambientais. Já Carletto e Pinheiro (2010, p. 519), afirmam que a inserção CTS contribui "para que os alunos desenvolvam percepções mais complexas da realidade e visões de mundo mais integradas, $[\ldots]$ "...

Apesar dos temas CTS, de acordo com a maioria dos referenciais da área, não terem uma forma estabelecida de escolha, nem envolverem os alunos na escolha do 
tema, são geralmente, temas atuais e muitas vezes do cotidiano. Em relação ao tema escolhido, que auxiliou no embasamento desta pesquisa, conclui-se que a temática permitiu principalmente discussões de aspecto social e de conceitos científicos envolvidos, o que possibilitou o desenvolvimento da cidadania e do cunho científico. Assim, é importante afirmar que as atividades construídas e desenvolvidas durante a aplicação da proposta contribuíram tanto para os alunos da educação básica quanto para a formação dos licenciandos envolvidos.

\section{CONSIDERAÇÕES}

Com base na pesquisa realizada, é válido apontar a importância do trabalho com propostas temáticas, uma vez que esta perspectiva contribui para a constituição da identidade profissional docente, permitindo que o futuro professor se torne capaz de desenvolver a autonomia e a capacidade de realizar atividades que contribuam para a construção do conhecimento dos alunos na escola.

No que se refere à interdisciplinaridade, pode-se observar que, apesar de reconhecer-se a dificuldade do trabalho interdisciplinar, acredita-se que a interdisciplinaridade pode contribuir para a desfragmentação do ensino, e que tal circunstância só pode ser alcançada através do trabalho coletivo.

Em relação ao PIBID, destaca-se que o projeto permite o desenvolvimento de novas metodologias e o estudo de referenciais teóricos, auxiliando a relação entre a teoria e a prática, possibilitando a reflexão sobre o papel do professor. Percebe-se também que no âmbito do PIBID, o subprojeto Física se configura como um importante espaço para o desenvolvimento do trabalho a partir de temas, pois apesar do assunto ser trabalhado em alguns componentes curriculares do Curso, o subprojeto trabalha com esta perspectiva de uma forma mais ampla, e compreensiva.

Por fim, admite-se que o PIBID contribuiu de maneira significativa para a elaboração da proposta desenvolvida durante a realização da pesquisa, pois em vários momentos os conhecimentos construídos através do projeto auxiliaram a autora, conhecimentos de cunho teórico, conceitual e também de prática de sala de aula, visto que o projeto valoriza a inserção dos licenciandos na escola. 


\section{REFERÊNCIAS}

AULER, D. Interações entre Ciência-Tecnologia-Sociedade no Contexto da Formação de Professores de Ciências. 2002. Tese (Doutorado em Educação) - Centro de Educação, Universidade Federal de Santa Catarina, Florianópolis, 2002.

AULER, D. Enfoque Ciência-Tecnologia-Sociedade: pressupostos para o contexto brasileiro. Ciência \& Ensino, São Paulo, v. 1, n. especial, 2008.

AULER, D.; DALMOLIN, A. M. T.; FENALTI, V. S. Abordagem Temática: Natureza dos temas em Freire e no enfoque CTS. Alexandria- Revista de Educação em Ciência e Tecnologia, Florianópolis, v.2, n.1, p. 67-84, mar. 2009. Disponível em: https://periodicos.ufsc.br/index.php/alexandria/article/view/37915. Acesso em: 06 jun. 2017.

BONATTO, A.; et al. Interdisciplinaridade no Ambiente Escolar. In: SEMINÁRIO DE PESQUISA EM EDUCAÇÃO DA REGIÃO SUL, 9., 2012, Caxias do Sul/RS. Anais [...]. Caxias do Sul/RS, 2012, p. 1-12. Disponível em: http://www.ucs.br/etc/conferencias/index.php/anpedsul/9anpedsul/paper/viewFile/2414/ 501. Acesso em: 28 ago. 2017.

BRAIBANTE, M. E. F.; WOLIMANN, E. M. A influência do PIBID na formação dos Acadêmicos de Química. Química Nova na Escola. São Paulo, v. 34, n. 4, p. 167-172, nov. 2012. Disponível em: http://qnesc.sbq.org.br/online/qnesc34_4/02-PIBID-9012.pdf. Acesso em: 10 jul. 2017.

BRASIL. Ministério da Educação e Cultura. Secretaria de Educação Média e Tecnológica. Parâmetros Curriculares Nacionais para o Ensino Médio (PCNEM), Brasília, 2000. Disponível em: http://portal.mec.gov.br/seb/arquivos/pdf/ciencian.pdf Acesso em: 28 maio 2017.

BRASIL. Ministério da Educação e Cultura. Secretaria da Educação Média e Tecnológica. PCN+ Ensino Médio: Orientações Educacionais Complementares aos Parâmetros Curriculares Nacionais - Ciências da Natureza, Matemática e suas Tecnologias, Brasília, 2002. Disponível em: http://portal.mec.gov.br/seb/arquivos/pdf/CienciasNatureza.pdf. Acesso em: 28 maio 2017.

BRASIL. Ministério da Educação. Secretaria de Educação Básica. Orientações Curriculares Nacionais para o Ensino Médio. Brasília: MEC, 2006. Disponível em: http://portal.mec.gov.br/seb/arquivos/pdf/book_volume_02_internet.pdf. Acesso em: 28 maio 2017.

CARLETTO, M. R.; PINHEIRO, N. A. M.. Subsídios para uma prática pedagógica transformadora: contribuições do enfoque CTS. Investigações em Ensino de Ciências, Porto Alegre/RS, v. 15, n. 3, p. 507 - 525, 2010,. 
DELIZOICOV, D.; ANGOTTI, J. A.. Física. 2. ed. São Paulo: Cortez, 1992.

DELIZOICOV, D.; ANGOTTI, J. A.; PERNAMBUCO, M. M. Ensino de Ciências: Fundamentos e Métodos. São Paulo: Cortez, 2002.

FAZENDA, I. C. A. Interdisciplinaridade: um projeto em parceria. São Paulo. Loyola, 2002.

HALMENSCHLAGER, K. R. Abordagem Temática no Ensino de Ciências: Algumas possibilidades. Vivências: Revista Eletrônica de Extensão da URI. Erechim, v. 7, n. 13. p. 10-21, Out. 2011. Disponível em: http://www2.reitoria.uri.br/ vivencias/Numero_013/artigos/artigos_vivencias_13/n13_0 1.pdf. Acesso em: 14 de maio 2017.

HUNSCHE, S. Docência no Ensino Superior: Abordagem Temática nas Licenciaturas da Área de Ciências da Natureza. 2015. Tese (Doutorado em Educação Científica e Tecnológica) - PPGECT/Universidade Federal de Santa Catarina, Florianópolis, 2015.

LEAL, P. F. L. Abordagem CTS na Formação Inicial de Professores: Um Olhar Para o Curso de Ciências Exatas Licenciatura. 2017. Trabalho de Conclusão de Curso (Ciências Exatas Licenciatura) - Universidade Federal do Pampa, Caçapava do Sul, 2017.

LOPES, A. C. Os Parâmetros Curriculares Nacionais para o Ensino Médio e a submissão ao mundo produtivo: o caso do conceito de contextualização. Educação e Sociedade - Revista de Ciências da Educação, Campinas, v. 23, n. 80, p. 386 - 400, set. 2002.

MARCONDES, M. E. R. et al. Materiais Instrucionais numa perspectiva CTSA: uma análise de Unidades Didáticas produzidas por professores de Química em formação continuada. Investigações em Ensino de Ciências, Porto Alegre, v. 14, n. 2, p. 281 298, 2009. Disponível em:

https://www.if.ufrgs.br/cref/ojs/index.php/ienci/article/view/359/226. Acesso em: 12 de abr. 2017.

MARQUES, S. G.; Enfoque CTS no Brasil: olhar sobre as práticas implementadas no Ensino Médio. 2015. Trabalho de Conclusão de Curso (Ciências Exatas Licenciatura) - Universidade Federal do Pampa, Caçapava do Sul, 2015.

MARTINS, I. P.; VEIGA, M. L. Uma Análise do currículo da escolaridade obrigatória na perspectiva da educação em Ciências. Lisboa: Instituto de Inovação Educacional, 1999.

MORAES, R.; GALIAZZI, M. C. Análise Textual Discursiva. 2. ed. rev. Ijuí: UNIJUÍ, 2007. 
NASCIMENTO, T. G.; von LINSINGEN, I. Articulações entre o enfoque CTS e a pedagogia de Paulo Freire com base para o ensino de ciências. Convergencia, México, v.13, n. 42. p. 95-116, 2006. Disponível em:

http://www.scielo.org.mx/scielo.php?script=sci_arttext\&pid=S140514352006000300006. Acesso em: 12 mar. 2017.

OLIVEIRA, T. C. Contribuições do PIBID na formação docente de acadêmicos do curso de Licenciatura em Ciências Exatas - Habilitação Química. 2014. Trabalho de Conclusão de Curso (Ciências Exatas Licenciatura) - Universidade Federal do Pampa, Caçapava do Sul, 2014.

PÁTARO, R. F; BOVO, M. C. A interdisciplinaridade como possibilidade de diálogo e trabalho coletivo no campo da pesquisa e da educação. Revista NUPEM, Campo Mourão, v. 4, n. 6, jan./jul. 2012. Disponível em:

http://rpem.unespar.edu.br/index.php/nupem/article/view/191. Acesso em: 14 de ago. 2017.

PINHEIRO, N. A. M.; SILVEIRA, R. F.; BAZZO, W. A. Ciência, Tecnologia e Sociedade: A relevância do Enfoque CTS para o contexto do Ensino Médio. Ciência \& Educação, Bauru, v. 13, n. 5, p. 71-84, 2007. Disponível em:

http://www.scielo.br/scielo.php?pid=S151673132007000100005\&script=sci_abstract\&tlng=pt. Acesso em: 14 ago. 2017.

SANTOS, W. L. P.; MORTIMER, E. F.. Uma análise de Pressupostos Teóricos da Abordagem C-T-S (Ciência-Tecnologia-Sociedade) no Contexto da Educação Brasileira. Ensaio Pesquisa em Educação em Ciências, Belo Horizonte, v. 2, n. 2, p. 133 - 162, 2000. Disponível em:

http://www.scielo.br/scielo.php?script=sci_arttext\&pid=S1983-21172000000200110. Acesso em:10 de jul. 2017.

STRIEDER, R. B. Abordagens CTS na educação científica no Brasil: Sentidos e perspectivas. 2012. Tese (Doutorado em Ensino de Ciências) - Instituto de Física e Faculdade de Educação, Universidade de São Paulo, São Paulo, 2012.

UNIVERSIDADE FEDERAL DO PAMPA. Projeto Pedagógico do Curso de Ciências Exatas e da Terra - Licenciatura. Caçapava do Sul, p. 33 - 40, 2013. Disponível em: http://cursos.unipampa.edu.br/cursos/cienciasexatas/pagina_fixa/ppc/. Acesso em: ago. 2017.

ZABALZA, M.A. Diários de Aula: um instrumento de desenvolvimento profissional. Porto Alegre: Artmed, 2004. 